\title{
Implementation challenges of social protection policies in four districts in Ghana: The case of the District Assembly Common Fund meant for Persons with Disabilities
}

\author{
Ronald Adamtey \\ Senior Lecturer \\ Department of Planning \\ Kwame Nkrumah University of Science and Technology, Kumasi, Ghana \\ E-mail: radamtey.cap@knust.edu.gh; radamteysekade@gmail.com

\section{Charles Yaw Oduro} \\ Senior Lecturer \\ Department of Planning \\ Kwame Nkrumah University of Science and Technology, Kumasi, Ghana \\ E-mail: cyoduro.cap@knust.edu.gh; yawoduro68@gmail.com

\section{Imoro Braimah} \\ Professor \\ Department of Planning \\ Kwame Nkrumah University of Science and Technology, Kumasi, Ghana \\ E-mail: ibraimah@knust.edu.gh; ibraimah2002@gmail.com
}

Submitted: October 3, 2017/ Accepted: May 18, 2018 / Published: June 8, 2018

\begin{abstract}
This study explores Ghana's implementation of a policy of two per cent of the District Assembly Common Fund (DACF) meant for persons with disabilities (PWDs) in four districts. It employed in-depth interviews with PWDs and officers in the District Assembly. The study revealed that the District Assemblies did not fully comply with directives from the central government to implement the policy. There were inconsistencies in the implementation of the policy and many PWDs received amounts that were less than they required. Further, fixed amounts were allocated to PWDs for different purposes and even though the purposes for requests were not clear, payments were made. The study recommends the need to compile and maintain a database of all PWDs in all the Districts in Ghana, implementing uniform format for allocation of the DACF to PWDs, providing support in the form of inputs rather than cash, and mobilising PWDs into cooperatives. The District Assemblies might consider engaging independent evaluators to monitor and evaluate the implementation of the policy to give the much-needed direction to the policy.
\end{abstract}

Keywords: District Assembly, District Assembly Common Fund, Persons with Disability, Ghana, social protection policy. 


\section{Introduction}

The need to address poverty has been the object of sustained scholarly debate and policy attention across the world. Organisations such as the World Bank, the United Nations Department of Economic and Social Affairs (UNDESA) and the United Nations Education and Cultural Organisation (UNESCO) have supported the implementation of pro-poor policies in developing countries where poverty is endemic and policies around disability and exclusion have been emphasised (UNDESA \& UNESCO, 2014; VOICE GHANA, 2014). Ghana has been a signatory to all these important United Nations (UN) and international protocols with regard to propoor policies for poverty reduction. The World Health Organisation (WHO) (2011) estimates show that more than a billion people in the world experience disability and they generally have poorer health, lower education achievements, fewer economic opportunities and higher rates of poverty than people without disabilities. Women and girls with disabilities are particularly vulnerable to abuse (UN, 2006).

Disability is a multi-dimensional concept that has been defined differently for different purposes such as employment, social security and welfare (ILO, 2011). The International Labour Organisation (ILO) (1983) has described PWDs as individuals whose prospects of securing, retaining and advancing in suitable employment are substantially reduced as a result of physical, sensory, intellectual or mental impairment. This definition focused mainly on the job security aspect of disability. For the United Nations Convention on the Rights of Persons with Disabilities (UNCRPD) (UN, 2006), disabled persons are those who have long term physical, mental, intellectual or sensory impairment, which in interaction with various barriers, may hinder their full participation in society on equal basis. The UN's definition of disability emphasises social, political and economic competencies.

According to Sen (2009), there is a relationship between disability and poverty in that, disability can lead to poverty whereas poverty can also create room for disability. According to Gwatkin 
Adamtey, R. Oduro, C. Y. \& Braimah, I./ Implementation challenges of social protection policies (2007), the risk of contracting disability-related diseases is mainly experienced by the poor in many developing countries due to their limited access to proper health care and rehabilitation services. In the same way, the extra cost incurred by persons with disability to meet their health needs and efficiency at work increases their risk of poverty.

The assertion that globally, PWDs tend to be poorer is consistent with a study conducted by the Organisation of Economic Development (OECD) in 2009 in developed countries. Of the 21 upper-middle and high-income countries studied, it was revealed that persons with disability within the working age bracket showed higher poverty rates than their counterparts who were without disability (OECD, 2009). It was evident from the study that the working-age of persons with disability population was twice as likely to be unemployed. In cases where they were employed, they worked part time except when they were highly educated to secure full time jobs. Even in such cases, they received lower wages.

A survey by the World Health Organisation in 15 developing countries revealed that households with disabled members incur more cost on health care as compared to households without disabled persons. The survey indicated that households with disabilities experienced higher poverty levels with non-health per capita consumption expenditures in five of the surveyed countries. Also, in Sierra Leone, households with persons with severe disability spent 1.3 times more on health care than households without disabled persons (WHO, 2O11).

The United Nations Development Programme recognises poverty as the lack of access to opportunity and violation of human dignity (UNDP, 2008). It uses human development index as a measure of poverty employing indicators such as literacy, education, health care, employment and other basic necessities. Given the evidence that disabled persons in developing countries are disadvantaged in terms of educational attainment, health care and employment opportunities (WHO, 2011), it follows that national and international communities must execute programmes to reduce 
poverty amongst the disabled and create equal opportunities for all.

\section{Global response to disability and pro-poor policies}

The Universal Declaration of Human Rights (UDHR) which constitutes the International Convention on Civil and Political Rights (ICCPR) and the International Convention on Economic, Social and Cultural Rights (CESCR) were among the first treaties after World War II that sought to protect the political/legal and social/economic rights of all persons as stated in Article 2 (Schulze, 2010, p. 15).

An earlier effort to bridge the gap by the UN led to the Declaration on the Rights of Mentally Retarded Persons in 1971 and the Declaration on the Rights of Disabled Person in 1975 (Guernsey et al., 2007). These declarations were more specific and targeted the disabled populace. The Declarations for Mentally Retarded Persons and Disabled Persons were made to create the platform for people with disability to enjoy their human rights. It stated that all human rights 'shall be granted to all disabled persons without any exception whatsoever and without distinction or discrimination on the basis of race, colour, sex, language, religion, political or other opinions, national or social origin, state of wealth, birth or and other situation applying either to the disabled person himself or herself or to his or her family' (Schulze, 2010, p. 16).

According to Schulze (2010), the provisions that seek to protect PWDs and their families constitute the first step for social recognition of PWDs and their families. In his view, this has firmly established the equality of rights of PWDs, which creates the opportunity to enjoy a decent life as normal and as full as possible. Other frameworks that support the rights of PWDs include the World Programme of Action Concerning Disabled Persons developed in 1982, the Tallinn Guidelines for Action on Human Resources Development in the Field of Disability in 1990, the Principles for the Protection of Persons with Mental Illness and the Improvement of Mental Health Care in 1991, the Standard Rules on the Equalisation of Opportunities for Persons with Disabilities in 1993 and the Human rights of persons with disabilities in 1998 
Adamtey, R. Oduro, C. Y. \& Braimah, I./ Implementation challenges of social protection policies (Guernsey et al., 2007).

According to Guernsey et al. (2007), although these documents including the Declaration on the Rights of Mentally Retarded Persons and the Declaration on the Rights of Disabled Persons highlight on the need to protect the rights of persons with disabilities at the international level, they were not binding due to the absence of any legal backing. The anticipated changes from these documents were not realised, as there were no laws guiding the implementation of the provisions enshrined in the documents.

A more comprehensive legally binding document directed to protect the rights of PWDs became a requirement for change as noted by the UN Secretary General that 'change comes rapidly when laws are in place' (Annan, 2006). In 2006 a Convention on the Rights of Persons with Disability (CRPD) was adopted with emphasis on the civil, cultural, political, social and economic rights of persons with disabilities (UN, 2006). As noted by Schulze (2010, p. 34), 'the purpose of the convention is to promote, protect and ensure the full and equal enjoyment of all human rights and fundamental freedom by all persons with disabilities and to promote respect for their inherent dignity.' The CRPD outlines measures to remove barriers and discrimination as well as promote the active participation of disadvantaged people in the life of their communities. These principles serve as the key to eradicate discrimination, segregation and exclusion of PWDs and at the same time create the platform for PWDs to exercise their rights and freedom.

Beyond these conventions, international development programmes, such as the Sustainable Development Goals (SDGs), also make provision for the protection of the rights and freedom of PWDs. The SDG 10 calls for 'reducing inequalities in income, as well as those based on sex, age, disability, race, class, ethnicity, religion and opportunity both within and among countries' (UN, 2016, p. 30). The principle of equal opportunity and the quest to reduce income inequalities among PWDs creates the avenue for them to undertake any economic activity which they deem fit. 
Adamtey, R. Oduro, C. Y. \& Braimah, I./Legon Journal of the Humanities 29.1 (2018)

\section{Disability and pro-poor policy implementation - Ghana's response}

Ghana has implemented a number of poverty reduction policies and pro-poor programmes aimed at improving the lives of the poor, vulnerable and excluded (see Republic of Ghana, 1998; 2003; 2005; 2011; 2013). Pro-poor strategies implemented include the Livelihood Empowerment against Poverty (LEAP), National Youth Employment Programme (NYEP) and the District Assembly Common Fund for PWDs.

Ghana's Ministry of Gender, Children and Social Protection (MoGCSP) initiated the LEAP programme in 2008 with the aim of eliminating poverty in the short-term and supporting long-term human capacity development. The LEAP initiative provides cash and free health insurance support to extremely poor households across the country. The selection criteria of eligible households included households with poor elderly persons and persons with disability who are unable to work. Although the free insurance policy covers the cost of health care for the beneficiaries, the cost of assistive devices for PWDs such as crutches, callipers, prostheses, lenses and hearing aid are not covered (Ghana Federation of the Disabled (GFD), 2008).

The NYEP was initiated in 2006 with the intention of reducing the rate of unemployment among the youth in the country. The initiative was motivated by the $26 \%$ rate of unemployment among the youth. The programme aims at providing training to encourage entrepreneurship among the youth. As stakeholders, the Ghana Society of the Physically Disabled was tasked to train persons with disabilities in the area of chalk production with a $€ 5$ million support from Danish International Development Agency (DANIDA). This support was used to establish the Aso-Kente factory (Ministry of Youth and Sports, 2013). However, according to the Ghana Federation of Disabled (GFD), there was inadequate participation of PWDs in the design and implementation of the project, leading to its collapse (GFD, 2008).

The Persons with Disability ACT, ACT 715, was passed by Ghana's Parliament in 2006. In line with this, each District 
Adamtey, R. Oduro, C. Y. \& Braimah, I./ Implementation challenges of social protection policies Assembly is tasked to allocate up to $2 \%$ of its share of the District Assemblies Common Fund (DACF) towards PWDs support and activities (Republic of Ghana, 2011). There is, however, evidence to suggest that access to the fund by PWDs has been challenging. It is difficult to monitor the number of PWDs who have benefited from it and the quantum of funds allocated to them.

To address this problem, the National Council on Persons with Disability (NCPD) was instituted in 2010 and guidelines were developed for the disbursement and management of the fund. Consequently, in accordance with the guidelines, all District Assemblies (DAs) were directed in 2011 to open a special bank account for the lodgement of the PWDs/DACF. Although this policy has been implemented since 2011, there have been few studies that assess the performance of the policy in order to inform the implementation process. The Annual Progress Report on the Implementation of the Ghana Shared Growth and Development Agenda (GSGDA) (2010-2013) (Republic of Ghana, 2013) recommended studies of this nature. This paper therefore seeks to explore the implementation issues around this policy and recommend measures to improve the implementation process by focusing on four districts, namely Ga West Municipal Assembly, Ho Municipal Assembly, Assin North District Assembly and Adansi South District Assembly.

\section{Study context}

Article 252(2) of the 1992 Constitution of the Republic of Ghana mandates Parliament to annually allocate not less than five per cent $(5 \%)$ of central government's revenue to the District Assemblies for development. The monies are expected to be paid into the District Assemblies' Common Fund (DACF) in quarterly instalments. Each District Assembly is required to allocate $2 \%$ of its share of the Fund to PWDs within its jurisdiction.

The aims of the DACF for PWDs are to: a) minimise poverty among PWDs especially those outside the formal employment sector; and b) enhance their social image through dignified labour. Thus, the fund seeks to empower PWDs economically, through the 
Adamtey, R. Oduro, C. Y. \& Braimah, I./Legon Journal of the Humanities 29.1 (2018) improvement of their sources of livelihood along with providing educational support for children, students and apprentices with disabilities. Again, the fund is to be channelled into the capacity building of various Organisations of Persons with Disabilities (OPWDs) to advocate for the right of their members, sensitise them on disability issues as well as provide technical aid and assistive devices for PWDs (Republic of Ghana, 2011).

Under the guidelines for disbursement of the DACF to PWDs, each MMDA is required to establish a Disability Funds Management Committee (DFMC) for the purposes of managing the fund. Generally the committee is responsible for vetting applications received from PWDs and OPWDs, monitoring and supervising the utilisation of the fund, and presenting reports on the management of the fund to the District Assembly and the NCPD.

\section{Study methodology}

In order to explore the decision-making processes around the allocation of the DACF to PWDs as part of the implementation arrangements at the district level, the case study approach to data collection and analysis was adopted. Consequently, officers of the District Assembly and PWDs shared their experiences with the implementation of the policy in the form of stories and narratives. The analysis focused on the period from 2011 to 2016, the period during which the NCPD developed and implemented the guidelines for the disbursement of the disability component of the DACF.

The study employed in-depth interviews with key officers who are directly involved in the the allocation and disbursement of the DACF. For each of these District Assemblies, the officers interviewed were the Municipal/District Chief Executive, Coordinating Director, Finance Officer, Planning Officer, Directors of Community Development and Social Welfare and the Budget Officer. For each Assembly, ten Assembly members were randomly sampled and interviewed.

The study also used key informants to identify leaders of PWDs who, with the assistance of the Directors of Community Development and Social Welfare, arranged focus group discussion meetings with the PWDs. Following the focus group discussions, the team visited PWDs who had used their support to set up 
Adamtey, R. Oduro, C. Y. \& Braimah, I./ Implementation challenges of social protection policies businesses and had further interviews at their business sites.

\section{Profile of selected districts}

Out of the 10 administrative regions in Ghana, four were randomly selected out of which one Assembly each was chosen for the study. The four Assemblies are the Ga West Municipal Assembly in the Greater Accra Region, Ho Municipal Assembly in the Volta Region, Assin North District Assembly in the Central Region and Adansi South District Assembly in the Ashanti Region (see Figure 1).

\section{Ho Municipality}

According to the 2010 Population and Housing Census 7,636 persons in the Ho municipality, representing about $4 \%$ of the total population had disabilities (Ghana Statistical Service, 2014; Ho Municipal Assembly, 2010). A disaggregation of the data indicated that sight-related impairments constituted the most common type of disability in the municipality, accounting for almost $29 \%$ of all disabilities. This was followed by physical and emotional disabilities, each of which accounted for about $19 \%$. The census data also indicated that, in relative terms, females with disabilities $(4.5 \%)$ were slightly more than males with disabilities $(4.1 \%)$.

\section{Ga West Municipality}

Persons with disability formed $2.5 \%$ of the total population in the Ga West Municipality in 2010. Ten per cent had hearing difficulty. The proportion of female disabled persons $(2.6 \%)$ was relatively higher than their male counterparts $(2.4 \%)$. This included sight and physical disabilities, which formed $50.4 \%$ and $19.4 \%$ respectively. Whereas speech was the major disability among the males $(58.8 \%)$, sight was the commonest among the females $(56.2$ $\%$ ). Furthermore, $51.4 \%$ of these persons with disabilities were employed although only $50.7 \%$ had attained basic level education. About $56 \%$ of those employed had emotional disability while 59 $\%$ of the unemployed recorded emotional disability. 


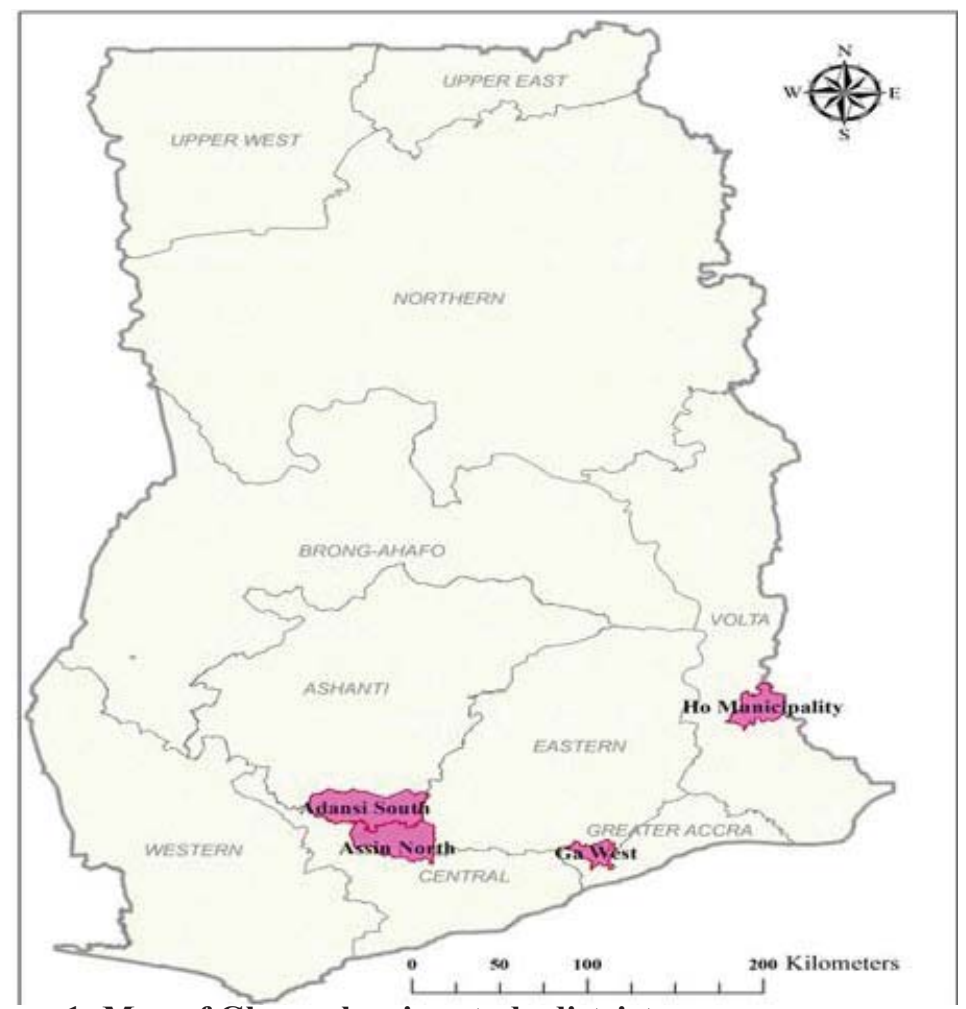

Figure 1: Map of Ghana showing study districts

Source: Department of Planning, Kwame Nkrumah UniversScience and Technology, 2016

\section{Assin North Municipality}

The number of persons with various types of disabilities in the Assin North Municipality was 7,539 and this accounted for $4.7 \%$ of the total population (Ghana Statistical Service, 2014). As is the case in Ho, sight-related disability was the most common, accounting for a quarter of all disabilities in the district. This is followed by emotional disability with $19 \%$ and physical disability with $16 \%$. The prevalence rate of disability was marginally higher among females than males. The proportion of the total district population that suffered from one form of disability or another was $4.8 \%$ among females and $4.6 \%$ among the males. 


\section{Adamtey, R. Oduro, C. Y. \& Braimah, I./ Implementation challenges of social protection policies}

Adansi South District

The 2010 Population and Housing Census revealed that 3,633 persons in the Adansi South district, representing 3.1\% of the total population had disabilities (Ghana Statistical Service, 2014). The percentage of disabled persons in the district $(3.1 \%)$ was relatively higher than the regional and national averages of $2.6 \%$ and $3.0 \%$ respectively. Also, there were slightly more males $(51.8 \%)$ with disabilities than females $(48.2 \%)$.

\section{Findings and discussion}

A number of very important issues emerged from the study need policy attention. The findings suggest that the implementation of this policy cannot be said to be successful. The issues include inadequate compliance with the implementation of the guidelines by the District Assemblies, inconsistency in the data organisation for the disbursement of the fund and limited coverage of beneficiaries. The rest are inadequacy of the amount disbursed, petty trading being dominant reason for making request by PWDs, the allocation of fixed amount for different purposes, and the allocation of monies without any clear purposes stated. These are discussed next.

\section{Inadequate compliance with the implementation guidelines}

Metropolitan, Municipal and District Assemblies commonly fail to adequately comply with central government directives (Adarkwa \& Adamtey, 2007; Dasmani, 2014) and this was found to be the case with the Guidelines for the Disbursement of the 2 $\%$ DACF allocation to PWDs. The focus groups discussions with PWDs in all the four districts revealed that the Assemblies did not fully comply with the directives issued by the NCPD. The inadequate compliance came in two main forms. The first was that the MMDAs were reluctant to release the funds to PWDs and the second was delays in the release of the funds by the Assemblies. 
Adamtey, R. Oduro, C. Y. \& Braimah, I./Legon Journal of the Humanities 29.1 (2018)

The Minister for Local Government and Rural Development had to write to all MMDAs to fully comply with the directives. In the letter, the Minister noted as follows:

My attention has been drawn to the non-compliance with the Guidelines issued in January 2010 on the disbursement of the two per cent (2\%) District Assemblies' Common Fund to persons with Disability by most Assemblies in spite of this Ministry's reminder letter dated $16^{\text {th }}$ July 2010 and $4^{\text {th }}$ May 2011. For the avoidance of doubt, this Ministry would like to invite the attention of all Assemblies to the provisions in the Guidelines and to ask for your strict compliance with the various sub-headings therein. Hon. Regional Ministers are kindly requested to instruct their Regional Monitoring Teams to also take up the inspection of the operations of the Fund in the Assemblies as part of their monitoring activities and submit a special report on the management of the fund to the Ministry. (Ghana Federation of Disabled, Ho, 2015)

We found that in line with the Minister's letter to the MMDAs, Associations of PWDs demanded to know the extent to which MMDAs had complied with the directive. Those in Ho for example made a formal request to the Ho Municipal Assembly on this issue. In their letter of inquiry, it is noted that:

The National Secretariat of the Ghana Federation of the Disabled (GFD) would like to inquire of the Ho Municipal Assembly's compliance with the Directive from the Honourable Minister of Local Government and Rural Development to all Honourable Regional Ministers and informing all Metropolitan/Municipal/District Chief Executives to ensure compliance with an earlier directive to open 
Adamtey, R. Oduro, C. Y. \& Braimah, I./ Implementation challenges of social protection policies separate Bank Account for the 2 percent of DACF for PWDs. (Ghana Federation of the Disabled, Ho, March 2016)

In the discussions with the officers of the District Assemblies, they noted that they had complied with the directives but added that delays in the release of the DACF to them had resulted in their own delay in disbursing the PWD component. The PWDs and the central government described these delays as 'noncompliance.' Some of them also noted that the Assemblies used the fund for emergency situations and later made resources available to be disbursed to PWDs.

\section{Inconsistency in data organisation for the disbursement of the fund}

The study revealed that there were inconsistencies in how the various districts organised their data on the allocations made to PWDs. This can undermine coordination, monitoring and evaluation at both the regional and national levels. For example, the Ho Municipal Assembly organised their data to show the amounts requested by PWD and amounts approved for them. There is additional information explaining the nature of the support and the purpose or use to which the amount requested would be put. For the Assin North District, the data were organised under the following columns: name of the disabled person, gender, community, type of disability, purpose of the request and amount approved. Significantly, a column had also been created for either the signature or thumbprint of the recipient. In the other Assemblies, no provision had been made for the PWD's signature to testify that they had received the support.

In terms of general information on PWDs in the districts, it was only the Assin North District that had comprehensive data. The Department of Social Welfare of the Assin North District had a comprehensive register to record the biographical data and other important information about each PWD, including their names and residential addresses, telephone contacts, type of disability, date of 
Adamtey, R. Oduro, C. Y. \& Braimah, I./Legon Journal of the Humanities 29.1 (2018)

disability and occupation. The rest included the level of education and the assistance required.

\section{Limited coverage of beneficiaries}

The data from the GFD, which were corroborated by discussions with the focus groups, suggest that the coverage of PWDs for support was limited. There are a good number of PWDs who had not been identified in the various districts (see Figures 2 and 3).

As shown in Figures 2 and 3, and based on the data provided by the Ghana Statistical Service (2014), PWDs to be supported in the Ho Municipality were 1970 people with physical disability, 872 deaf and 2929 blind people. Out of these numbers, Ho could only support $3 \%, 4 \%$ and $4 \%$ respectively for these numbers. In the Assin-North District, 1230 PWDs had physical disability, 790 had hearing/deafness challenges and 1870 had sight disability, yet the Assin-North could only support $14 \%, 26 \%$ and $16 \%$ respectively. This low coverage was not different from what we found in the $\mathrm{Ga}$ West Municipality and the Adansi South District (see Figures 2 and $3)$.

While the beneficiaries were few, we also found that the geographical coverage was limited as many of the beneficiaries were from the major towns and the district capitals. Many PWDs in the rural settlements and villages remote from the district capitals were not covered. This finding is supported by one of the high profile officers at the Ho Municipal Assembly. In the view of this officer,

As at 2011 about $80 \%$ of beneficiaries of the DACF were in the Ho Township. What about other settlements in the Ho Municipality? This raises questions about whether adequate numbers of PWDs are covered under the programme (High profile officer, Ho, March 2016). 
Adamtey, R. Oduro, C. Y. \& Braimah, I./ Implementation challenges of social protection policies

In a discussion with leaders of the GFD, one of them noted that 'there could be many disabled persons residing in the smaller settlements scattered all over the districts that could not be reached due to poor accessibility. Many of the roads are in very bad condition and there are no transport services to enable us identify and register them' (Leader, GFD).

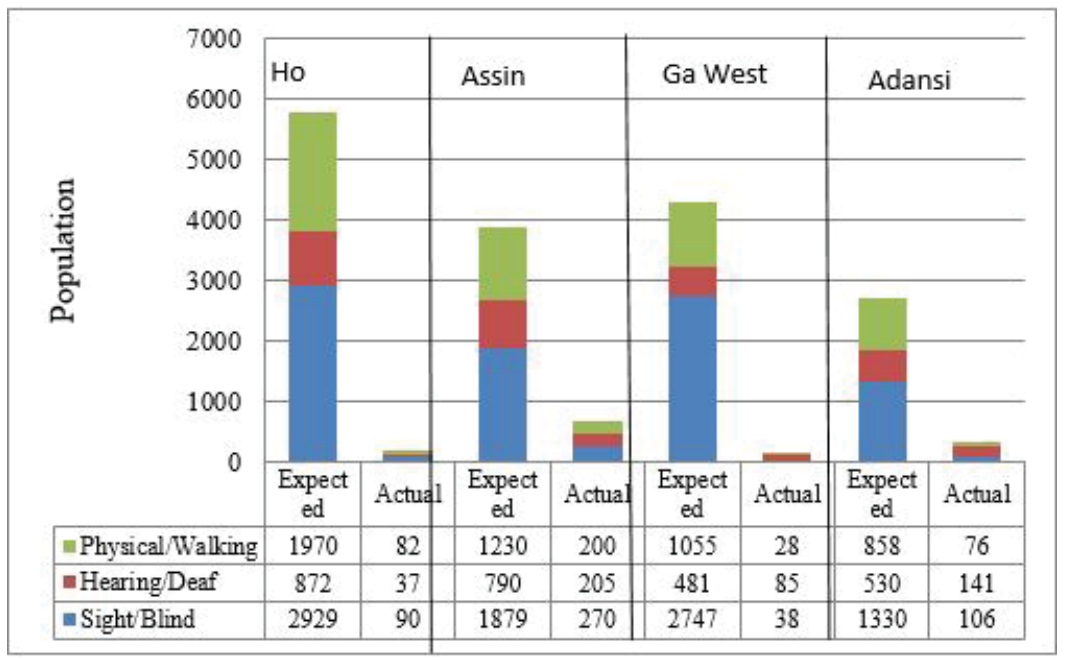

Figure 2: Population of PWDs and actual numbers of beneficiaries of the fund from 2011 to 2015.

Source: Authors' construct, August 2017 


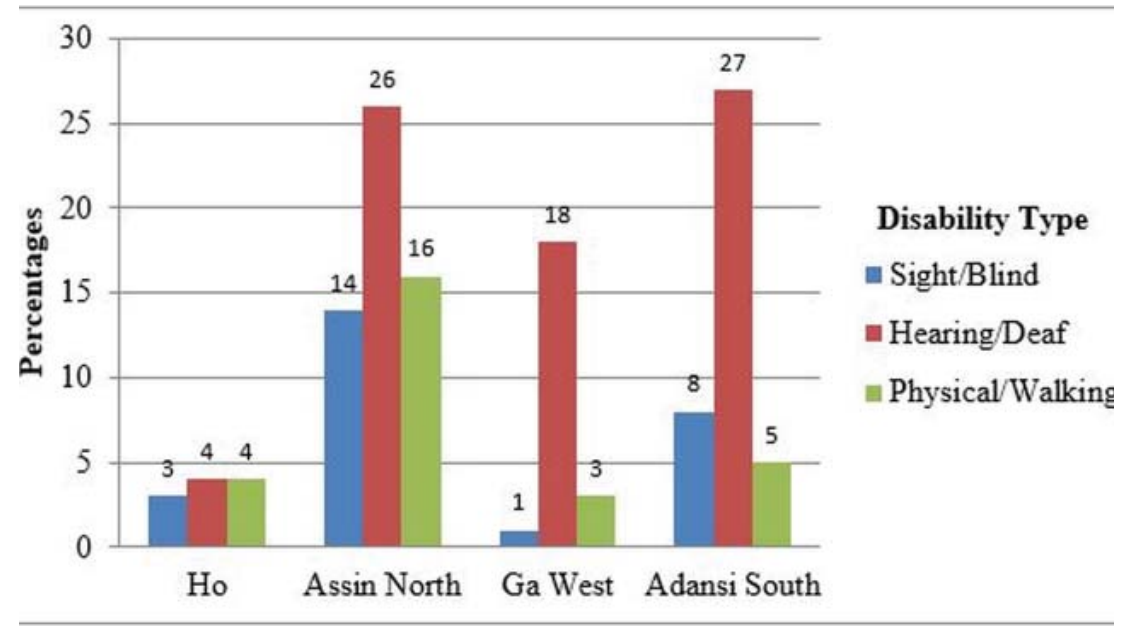

Figure 3: Actual proportions of beneficiaries of the fund from 2011 to 2015. Source: Authors' construct, August 2017

We found similar reasons from all the districts, all suggesting that there could be many persons with disability who had not yet benefitted from this policy.

\section{Insufficiency of disbursed amounts}

In about $80 \%$ of the cases, the full amount that the PWDs requested was not approved. The question this raises is whether the approved amounts could have the necessary impact by enabling PWDs undertake planned activities. In the case of Ho, the data on disbursements during the $1^{\text {st }}$ and $3^{\text {rd }}$ quarters of 2014, and the $1^{\text {st }}$ and $2^{\text {nd }}$ quarters of 2015, all confirm the fact that the full amounts were not approved. The disbursement data in the $1^{\text {st }}$ quarter of 2014 and 2015 show that up to $35 \%$ of PWDs did not receive up to half of the amounts they requested for educational/vocational training. In the same period, up to $95 \%$ of PWDs did not receive up to half of the amounts they had requested for them to engage in income generation activities. For example in the Assin North District, in the $2^{\text {nd }}$ quarter of 2011 , out of the 14 beneficiaries who were deaf, only 
Adamtey, R. Oduro, C. Y. \& Braimah, I./ Implementation challenges of social protection policies one was allocated $\mathrm{GHC}^{1} 500^{2}$ (i.e. about USD 119.62) for trading purposes. The remaining beneficiaries received between $\mathrm{GHC100}$ and GHC250 for activities such as soap making, hairdressing, welding, dressmaking and carpentry.

This concern has been raised by the various GFDs in all the districts. For example, in Ho, the Disability Fund Management Committee indicated in their report to the Ho Municipal Assembly that:

The Committee observed that the amounts allocated to each individual for income generation activities were not making the needed impacts because they were small. It was also observed that group income generation activities were better because they attracted higher amounts that could sustain their projects (GFD, Ho, March 2016).

During the last quarter of 2011, two applicants in the Ho Municipality who requested for GHC3000 and GHC2000 were both given GHC300 each. About $80 \%$ of the PWDs interviewed in all the districts indicated that their major challenge was that they were not given the full amounts they needed to enable them achieve the purposes for which the funds were requested. Some of the views expressed include the following:

I requested for $\mathrm{GHC} 2500$ to put up a kiosk to sell my flowers. I was given GHC300 and because this is not even up to half of the money I needed, I have used it for feeding (Person with Walking Difficulty, Ga West, March 2016).

I wanted GHC2000 to buy hair dryers and washers for my salon but they gave me only GHC200. I have bought just the washer and a chair but I cannot use

1 GHC stands for Ghana Cedi.

2 The averaged GHC-USD exchange rate for the period under review was GHC4.1798= 1 USD. 
Adamtey, R. Oduro, C. Y. \& Braimah, I./Legon Journal of the Humanities 29.1 (2018)

them so they are in my room covered with dust and I do not know when I will get the additional money to be able to set up and start work (PWD, Ho, March 2016).

\section{Seed capital for petty trading as dominant reason for making request}

About $80 \%$ of the applicants under income generation activities requested for seed capital for petty trading. The petty trading activities essentially involved 'buying-and-selling'. One of them noted thus 'I am already selling plastic containers and I wanted some more money to expand my business.'

Although these petty trading activities/businesses have the potential to make the applicants earn income directly, they do not have strong multiplier effects in terms of creating jobs for others. According to the Keynesian argument of multiplier effects, there is the need to invest in ventures that can create direct jobs. This implies investing in production rather than retailing. This way, it is possible to sustain the investment.

\section{Allocation of the same (fixed) amounts for different purposes}

Another finding was that the Assemblies made a flat or uniform allocation to all PWDs in spite of the fact that the applicants needed the support for different purposes. For example, during the $2^{\text {nd }}$ quarter of 2011, Assin North gave all 20 visually impaired applicants GHC300 each although the purposes for their requests differed. While some wanted the support for trading, others wanted it for fish-farming and or livestock production. This brings into question the allocation criteria used. In fact in Ho, a request was made for GHC1000 for fish farming and the Committee noted that the amount requested fell below the technically feasible sum of GHC35000. The purpose was changed to petty trading and GHC1000 was granted. This suggests that the GHC300 given for fish farming in Assin North was unrealistic.

In some cases, the same activities were indicated as reasons for requesting the support and yet the amounts given varied. For 
Adamtey, R. Oduro, C. Y. \& Braimah, I./ Implementation challenges of social protection policies

example, in the Assin North's $2^{\text {nd }}$ quarter of 2011 allocation, we found that allocations of GHC100, GHC200, GHC300, GHC500 and GHC600 were made to the beneficiaries for the same activity. Similar cases were recorded in the last quarter of 2012 when beneficiaries for farming were given between GH200 and GHC325. Those for trading were given between GHC200 and GHC250. Similar allocations were made in Assin North during the $3^{\text {rd }}$ and $4^{\text {th }}$ quarters of 2014. The same was reported for the April 2015 allocations where each beneficiary was allocated GHC400 for activities ranging from education (payment of bills) to trading, assistive devices and farming.

\section{Unclear purpose yet allocation of different amounts}

Although the guidelines specify that allocations should be made in line with the various objectives, the study found that some of the Assemblies did not strictly comply and made allocations to PWDs without stating the purpose. For example in the $1^{\text {st }}$ Quarter of 2012, Assin North made allocations for assistive devices without indicating the kind of device. The allocations made ranged between GHC400, GHC500, GHC600 and GHC1000.

We also found that some allocations were made with 'no purpose' stated in Ho. Although by 2011, the guidelines had spelt out the purposes to include income generation activities, education, vocational training and apprenticeship, health assistive needs as well as organisational development, we found that allocations were done with no purpose in September 2012 and July 2012. Amounts allocated ranged between GHC100 and GHC800. The same was done in the last quarter of 2015. So what was the basis for the allocations then?

Similarly, in the $2^{\text {nd }}$ quarter of 2013, Assin North made allocations ranging between GHC200 and GHC500 without any purpose indicated yet there were variations in the amounts allocated to PWDs. For example, out of the 72 beneficiaries, one person was allocated GHC500 and another allocated GHC400 without any clear basis. 
Adamtey, R. Oduro, C. Y. \& Braimah, I./Legon Journal of the Humanities 29.1 (2018)

In the view of the GFD and some high profile officers of the Assembly, this could affect the policy in two ways. The first is that the poverty reduction objective of the policy might not be achieved. The second is that this practice could be an avenue for corruption. One of them noted that:

The purposes for allocating the funds need to be stated so that we will be able to know if the fund is making the necessary impacts in that direction. It will also make it possible to hold fund managers and District Assemblies to account and help to eliminate corrupt practices (PWD, Ga West, March 2016).

How the money is allocated is questionable if you just state that it is for assistive devices. We need to know what kind of assistive devices and for whom. We must 'know the types of disabilities here so that we can determine those who need what kind of assistive devices (PWD, Adansi South).

We found a model in Ho that is worthy of emulation. Here, a request was made for GHC1400 in 2013 to purchase clutches, callipers and shoes for 10 people at GHC140 each. The Fund Management Committee approved and granted the request following cost confirmation from the Orthopaedic Hospital at Nsawam and the Committee ensured that the cheque was paid to the Hospital. Similarly, Ho specified the assistive devices in the $1^{\text {st }}$ quarter of 2014 and $1^{\text {st }}$ quarter of 2015 for purposes such as the replacement of artificial limb, purchase of special glasses for person with low vision, purchase of wheel chair, support for corrective surgery and physiotherapy. Given that PWDs who need the various types of assistive devices are known, the Ho model facilitates monitoring and evaluation. 
Adamtey, R. Oduro, C. Y. \& Braimah, I./ Implementation challenges of social protection policies

\section{Measures to improve implementation of the policy}

\section{Compilation of database of all PWDs in all the districts in Ghana}

The study recommends that all MMDAs must undertake a complete survey to map out all PWDs within their jurisdictions. This mapping exercise must produce a database of all PWDs with their bio-information including the categories/forms of disability. Based on the forms of disability, the profile must present an analysis of the capacities and capabilities of each of them in terms of the kind of economic activities they can engage in. Data so gathered can then be used to direct the fund to support PWDs in more productive businesses that have the potential to yield multiplier effects on other PWDs. Those who cannot do anything due to the nature of their disability, could then be given direct cash transfers for survival. While this database can help increase the coverage of beneficiaries, PWDs will see themselves as being part of the community's development process and this can encourage them to participate actively in the process. In addition, the distribution of meagre amounts can be eliminated and more viable projects can be funded to attain impactful results.

\section{Implementation of uniform format by all districts for allocating the DACF to PWDs}

The National Commission on Persons with Disability needs to develop a uniform format for use by all Assemblies to record all allocations of the District Assembly Common Fund made to beneficiaries. This template can serve monitoring and evaluation purposes. It can also be used by the Disability Fund Management Committee to present annual reports to the general assembly. It will also aid in monitoring at the national level and to evaluate the utilisation of the fund. Issues of allocation without purpose can be addressed. To further yield positive results and improve transparency, the Assemblies must be given basic training of expected mode of recording fund allocation at the district level. Punitive measures should be instituted against non-compliant districts that misapply or 
Adamtey, R. Oduro, C. Y. \& Braimah, I./Legon Journal of the Humanities 29.1 (2018) misdirect allocated funds. This way, the work of the Disability Fund Management Committee, officials of both the Department of Social Welfare and Community Development and the District Assembly will be made easier, less complicated and more transparent.

\section{Provision of support in the form of kits, equipment or inputs rather than cash}

In order to minimise the misapplication of funds by PWDs, the Assemblies together with their Departments of Social Welfare and Community Development might want to provide the support in the form of kits, equipment and inputs that are needed by the PWDs. The Assembly can procure inputs such as hair dryers, sewing machines, tables and chairs for the PWDs. PWDs who apply for funds to set up hairdressing salons can be given the hairdryers and the other inputs needed. Similarly, seamstresses and tailors can be given sewing machines. Those who receive this seed support must be made to make future contributions back to the district Disability Fund to make it more sustainable. Beneficiaries must also be made to employ other disabled persons as apprentices and train them to ensure the multiplier effect of the allocation on other PWDs.

\section{Mobilisation of PWDs in cooperatives for support}

District Assemblies and their Social Welfare and Community Development Departments might consider adopting the model we found in the Ho Municipality to provide support for PWDs. In the Ho model, PWDs had been mobilised into groups and supported to engage in the production of handicrafts for sale. This model has a number of benefits. Firstly, it makes for the efficient application of the funds even if they are not very substantial amounts. Secondly, such production centres and the groups can pool their energies to support one another. Thirdly, they can serve as centres for costeffective apprenticeship training for other PWDs. Finally, these centres could provide opportunities for communal living, which can produce and strengthen social capital among PWDs. 
Adamtey, R. Oduro, C. Y. \& Braimah, I./ Implementation challenges of social protection policies

Engagement of private consultants to undertake regular monitoring and evaluation

For the effective monitoring and evaluation of the impact of the DACF on PWDs and to understand how the District Assemblies are faring, the Assemblies need to engage private consultants to periodically undertake this exercise. While this approach can allow the Assembly to receive a more balanced account on their performance, it will also relieve the Assemblies of the burden of research capacity and make them concentrate on their core mandate of providing basic services to their citizens and poverty reduction efforts.

\section{Mobilisation of resources through awareness creation by faith and religious groups about PWDs}

Among the ways that District Assemblies can raise additional resources to support PWDs is to use faith-based and religious groups in the districts. Through the Social Welfare and Community Development Departments, the Assemblies could set up Joint Community Development Committees charged with the responsibility of creating awareness about disability, involvement of the entire community to support PWDs and seeing to the mobilisation of financial and other resources to support PWDs. Membership of these committees should be drawn from each of the various religious or faith-based groups in the district, the various categories of PWDs, and the traditional authority. Additionally, the Director of the Social Welfare and Community Development Department, Coordinating Directors of the Assemblies and three elected representatives from the General Assembly should serve on these committees. As a starter, all faith-based and religious groups should be encouraged to either make voluntary contributions or allocate to the welfare of PWDS a specified percentage of the funds they realise from their members' weekly contributions. This strategy could produce a number of benefits. The first is that it can change the negative perception that the society has about disability given that some even see disability as punishment for one's evil 
doing in the past pre-birth life or present lifetime. Secondly, the involvement of faith-based groups in the life of PWDs can increase the society's acceptance of and love for PWDs. The third potential beneficial consequence is that it can strengthen the bond between abled and disabled persons and engender the constant flow of voluntary contributions, from within and outside the community, to the cause of PWDs in the districts.

\section{Conclusion}

Our study set out to explore Ghana's implementation of a policy of 2 percent of the District Assembly Common Fund meant for PWDs in four districts. The findings have shown that, through the improvement of their sources of livelihood along with providing assistive devices for many PWDs, the policy has the potential to contribute in many ways to empower PWDs economically. The implementation process is, however, fraught with many challenges. Findings from this study contribute to increase our understanding of the evidence that access to the fund by PWDs has been challenging. The issues confronting the implementation of this policy include inadequate compliance with the implementation guidelines, inconsistency in data organisation for the disbursement of the fund, limited coverage of beneficiaries and the inadequacy of amounts disbursed. The rest are allocation of the same amounts for different purposes, allocations made with no clear purposes stated and many of the PWDs requesting the money for petty trading that might not produce adequate multiplier effects.

In order to improve the implementation of this policy, the following policy steps might help: the need to compile database of all PWDs in all the districts in Ghana, the implementation of uniform format by all districts for allocating the DACF to PWDs, the provision of support in the form of kits, equipment or inputs rather than cash and the mobilisation of PWDs in cooperatives for support. In addition, District Assemblies must engage private consultants to undertake regular monitoring and evaluation of the implementation of this policy to enable them understand the performance of the policy. District Assemblies must also mobilise 
Adamtey, R. Oduro, C. Y. \& Braimah, I./ Implementation challenges of social protection policies additional resources through awareness creation with faith and religious groups about PWDs.

It must be noted that it is unlikely that the policy can contribute towards improving the lives of PWDs as long as the issues identified in this study remain unresolved. The policy impact will be inadequate unless the implementation arrangements are made effective. This study confirms a well-known problem in Ghana and in many poor countries, which has more to do with the implementation of policies than the inadequacy of policies. The implementation of policies should therefore be given the needed attention by all stakeholders. Once this is done, the aims of the DACF for PWDs which is to minimise poverty among PWDs especially those outside the formal employment sector might be achieved and the social image of PWDs can be enhanced as envisaged by the policy. 
Adarkwa, K. K., \& Adamtey, R. (2007). State directives, fiscal decentralisation and regional development in Ghana. Regional Development Dialogue, 28(1), 76-89.

Annan, K. (2006). Secretary General hails adoption of landmark convention on rights of people with disability, official statement of the UN Secretary General SG/SM/10797 [Interview] (13 December 2006).

Dasmani, L. (2014). Ghana News Agency: Ghana disabled fund managers violate guidelines. Retrieved from http://www.ghananewsagency.org,

Ghana Federation of Disabled. (GFD). (2008). Problems with access to the DACF for assistive devices. Unpublished report by GFD on Assin North District.

Ghana Federation of Disabled. (GFD, Ho). (2014). Compliance with directive on the implementation of guidelines for the disbursement of the two (2) percent DACF allocated to persons with disability (A letter with reference number $682003 / 667911$ dated $14^{\text {th }}$ February 2014 written to all Regional Ministers, Metropolitan, Municipal and District Chief Executives).

Ghana Federation of Disabled. (GFD, Ho). (2016). Enquiry-opening of separate bank account for the $2 \%$ district assemblies' common fund for persons with disability. Unpublished. Ho: Ghana Federation of Disabled

Ghana Statistical Service. (2014). 2010 Population and housing census: District analytical report, Ho Municipality. Accra: Ghana Statistical Service.

Guernsey, K., Nicoli, M., \& Ninio, A. (2007). Convention on the rights of persons with disability: Its implementation and relevance to the World Bank, Washington, DC: World Bank.

Gwatkin, D. (2007). Socioeconomic differences in health, nutrition, and population within developing countries. Washington, DC: World Bank.

Ho Municipal Assembly. (2010). Medium-term development plan 2010-2013. Ho: Ho Municipal Assembly.

ILO. (1983). Vocational rehabilitation and employment (disabled persons) convention (No. 159). Geneva, 69th ILC session (20 Jun 1983). Retrieved from http://www.ilo.org/dyn/normlex/en/f?p=NORMLEXP UB:12100:0::NO::P12100 INSTRUMENT ID:312304

ILO. (2011). Disability in the workplace: Employers' organisations and business networks. Retrieved from www.businessanddisability.org/im ages/pdf/working_paper_n6.pdf

Ministry of Youth and Sports. (2013). Ministerial impact assessment and review committee on Ghana youth employment and entrepreneurial agency. Retrieved from http://datablog.peacefmonline.com/pages/ blog/32/doc.pdf 
Adamtey, R. Oduro, C. Y. \& Braimah, I./ Implementation challenges of social protection policies

OECD. (2009). Sickness, disability and work; keeping on track in the economic downturn, (Background Paper, High -Level Forum, Stockholm, 14-15 May 2009). Retrieved from https://www.oecd.org/ els/emp/42699911.pdf

Republic of Ghana. (1998). Ghana-vision 2020: programme of action for the first medium-term development plan (1997-2000), Accra: NDPC.

Republic of Ghana. (2003). Implementation of the Ghana poverty reduction strategy: 2003 Annual progress report, Accra: NDPC.

Republic of Ghana. (2005). Growth and poverty reduction strategy (GPRS II) (2006-2009), 1: Policy Framework. Accra: NDPC.

Republic of Ghana. (2011). National council on persons with disability: Guide lines for the disbursement and management of the District Assembly Common Fund for persons with disability. Accra: Ministry of Social Welfare.

Republic of Ghana. (2013). Implementation of the Ghana shared growth and development agenda (GSGDA), 2010-2013: 2013 Annual Progress Report, Accra: NDPC.

Schulze, M. (2010). Understanding the UN on the rights of persons with disabilities. 3rd ed. New York: Fedex Office and Print Service.

Sen, A. (2009). The idea of justice, Cambridge, MA: The Belknap Press of Harvard University.

UNDESA, \& UNESCO. (2014). United Nations expert group meeting on disability data and statistics, monitoring and evaluation: The way forward - A disability-inclusive agenda towards 2015 and beyond Paris, France (8 -10 July 2014). A Report presented to the secretariat to the convention on the rights of persons with disabilities division for social policy and development, United Nations Department of Economic and Social Affairs in collaboration with United Nations Educational, Scientific, and Cultural Organization. Retrieved from http://www.un.org/disabilities/documents/egm2014/ EGM_FINAL_08102014.pdf

UN. (2006). International convention on the rights of persons with disability; Some facts about persons with disability. Retrieved from http://www. un.org/disabilities/convention/pdfs/factsheet.pdf

UN. (2016). Sustainable development goals report, New York: United Nation. UNDP. (2008). Human development report: 2007/2008 Human development index ranking. Retrieved from https//www.hdr.undp.org

Voice Ghana. (2014). Political governance for persons with disabilities: A study on the level of participation of persons with disabilities in local governance. Retrieved from http://voiceghana.org/downloads/Re search $\% 20$ on $\% 20$ Political\%20Governance $\% 20$ for\%20PWDs.pdf

WHO. (2011). World report on disability, Retrieved from

http://www.who.int/disabilities/world_report/2011/en/ 